\title{
The Correlation of Infectious and Inherent Agents with Acute Myocardial Infarction in Patients of Teaching Hospitals in Qazvin in 2013
}

\author{
Narges Dehghan Nejad1, Leila Mostafaei', Farzaneh Jahanbakhshi', Fatemeh Rashvand1, \\ Mahmoud Heidari Alipour ${ }^{1}$, Mohammad Reza Saroukhani2 ${ }^{*}$ \\ ${ }^{1}$ Qazvin University of Medical Sciences, Qazvin, Iran \\ ${ }^{2}$ Department of Laboratory Sciences, Qazvin University of Medical Sciences, Qazvin, Iran \\ Email: ${ }^{*}$ mrsarookhan@QUMS.ac.ir
}

Received 20 July 2015; accepted 6 August 2015; published 11 August 2015

Copyright (C) 2015 by authors and OALib.

This work is licensed under the Creative Commons Attribution International License (CC BY). http://creativecommons.org/licenses/by/4.0/

(c) (i) Open Access

\section{Abstract}

Background: Acute myocardial infarction (AMI) is one of the most common reasons of hospitalization in western countries. The rate of early mortality (the first $\mathbf{3 0}$ days) caused by AMI is about $30 \%$. Many studies have introduced the infection with Helicobacter pylori and mycoplasma pneumonia as causes of AMI. However, some other studies on the effect of mycoplasma pneumonia, $\mathrm{He}$ licobacter pylori, and blood group on the incidence of heart attack showed contradictions that might be due to the ethnical and racial heterogeneities. Therefore, this study was conducted to determine the correlation of the infection with Helicobacter pylori and mycoplasma pneumonia and blood group with AMI in Qazvin Province, Iran. Objectives: In this respect, the infection with Helicobacter pylori and mycoplasma pneumonia can be taken as a risk factor for AMI thereafter if there is a strong correlation between infection with Helicobacter pylori and mycoplasma pneumonia and AMI, and also the high-risk blood groups can be identified, and consequently, risk factors for AMI be reduced through early treatment. Materials and Method: This case-control study was performed in teaching hospitals in Qazvin. After completing the sample size in both groups (blood serum of 90 patients with a history of infarction as the case group and blood serum of 90 other people that matched for age and sex with the first group and had no history of infarction as the control group), the studies were performed to determine the correlation of AMI with mycoplasma pneumonia through the level of IgG antibody, with Helicobacter pylori through the level of relevant antibodies (IgA and IgG), and with blood groups through back-type method. Results: Men and women of the case group comprised $63.3 \%$ and $36.7 \%$, respectively, and men and women of the control group comprised $\mathbf{6 7 . 8 \%}$ and $32.2 \%$, respectively. The level of Helicobacter pylori IgG was considered negative in $1.1 \%$, borderline in $5.6 \%$, and positive in $93.3 \%$ in the case group and neg-

\footnotetext{
${ }^{*}$ Corresponding author.
}

How to cite this paper: Nejad, N.D., Mostafaei, L., Jahanbakhshi, F., Rashvand, F., Alipour, M.H. and Saroukhani, M.R. (2015) The Correlation of Infectious and Inherent Agents with Acute Myocardial Infarction in Patients of Teaching Hospitals in Qazvin in 2013. Open Access Library Journal, 2: e1656. http://dx.doi.org/10.4236/oalib.1101656 
ative in $5.6 \%$, borderline in $10 \%$, and positive in $84.4 \%$ in the control group. According to the Chi-square test, the difference between the two groups was significant $(P<0.05)$. However, the results showed that the level of Helicobacter pylori IgA was negative in $20 \%$, borderline in $26.7 \%$, and positive in $53.3 \%$ in the case group and negative in $12.2 \%$, borderline in $20 \%$, and positive in $67.8 \%$ in the control group. Based on the Chi-square test, the difference between the two groups in this regard was not significant $(P>0.05)$. The level of mycoplasma pneumonia IgG in the samples was negative in $17.8 \%$, borderline in $5.6 \%$, and positive in $76.7 \%$ in the case group and negative in $\mathbf{2 7 . 8 \%}$, borderline in $2.2 \%$, and positive in $\mathbf{7 0 \%}$ in the control group. Based on the Chi-square test, there was no significant difference between the two groups in this regard $(P>0.05)$. The results on testing the $A B O$ blood groups showed that $23.3 \%, 21.1 \%, 27.8 \%$, and $27.8 \%$ of the patients with $A M I$ in the case group had the blood group $0, A B, A$, and $B$, respectively, and $30.7 \%, 13.6 \%$, $34.1 \%$, and $21.6 \%$ of the people in the control group had the blood group $0, A B, A$, and $B$, respectively. The analysis of results did not show a significant difference between case and control group in terms of $\mathrm{ABO}$ blood groups $(\mathrm{P}>\mathbf{0 . 0 5})$. Conclusion and Recommendation: This study did not show a significant difference between the two groups in terms of the level of IgG except infection with Helicobacter pylori. However, more studies should be performed at local and national levels in order to find the role of risk factors of AMI in each region.

\section{Keywords}

Helicobacter pylori, Mycoplasma, ABO Blood Groups, Acute Myocardial Infarction, Qazvin

Subject Areas: Cardiology

\section{Background}

Acute myocardial infarction (AMI) is one of the most common reasons for hospitalization in western countries. The rate of early mortality (the first 30 days) caused by AMI is about 30\%, as half of these deaths occur before patients arrive at the hospital. Moreover, about one out of 25 persons who survive in the initial hospitalization would die in the first year after AMI [1]. The survival rate particularly decreases in old patients (over 75 years old). Although the patients' survival has increased following the hospitalization over the last two decades, $5 \%$ $10 \%$ of survivors die in the first year after AMI, and they still suffer the risk of death and relapse of AMI.

Coronary artery atherosclerosis is the most important predisposing factor for acute myocardial infarction, and various risk factors have been introduced for it, including lipid metabolism disorders, changes in the concentration of lipoproteins, cholesterol, and leptin, genetic factors, diabetes, age, sex, and smoking habits. In recent years, numerous studies have examined the involvement of chronic infections in atherosclerosis, and most of these studies have also examined chronic inflammation caused by persistent infections with some microorganisms. Inflammation of vessel wall is an important factor in development of atherosclerosis, instability of arterial clots (atheroma), and rupture of plaques after local thrombosis that are clinically manifested by acute coronary syndrome. Vascular endothelial cell injury is the major factor in development of atherosclerotic plaques and often results in fibro-proliferative inflammatory response [2].

Helicobacter pylori is a helical-shaped, gram-negative, facultative, flagellated, and motile bacterium that causes different gastrointestinal conditions.

Helicobacter pylori causes immune cells to increase serum antibodies, including IgA, IgM, and IgG. Many studies have examined the role of Helicobacter pylori as a risk factor for coronary artery disease, and some reported its significant role. It is believed that HP causes coronary artery disease through increasing the activity and accumulation of platelets [3]-[8].

Mycoplasmas are the smallest free organisms without hard cell wall. These bacteria have a three-layered membrane containing sterol. Mycoplasma pneumonia causes atypical pneumonia in humans. Mycoplasma firstly penetrates into the epithelial cells of the airways. It destroys the cells and triggers an inflammatory reaction throughout the area and, in some cases, penetrates into the blood flow. Mycoplasmas need cholesterol to grow and can cause endothelial dysfunction [9] [10]. Leukocyte migration along with increased monocyte binding, 
failure to produce nitric oxide, dilation of vessels, and gradual progress of the inflammation occur following the endothelial dysfunction [10].

The activation of endothelial cells by pro-inflammatory cytokines with infectious agents reduces the antithrombosis function of heart tissue [11] [12]. In other words, the endothelial dysfunction arising from the inflammation disturbs the balance of normal cellular activity in the endothelium, affects the anticoagulant property of the tissue negatively, and develops pre-coagulation conditions [12] [13]. Chlamydia pneumoniae and mycoplasma pneumonia have been presented as bacterial risk factors for AMI, in several studies that show their role in development of atherosclerosis and the subsequent AMI [10] [14]-[19].

Some studies introduced the ABO blood groups as the genetic factors involved in the incidence of AMI. The ABO blood groups were the first blood groups introduced by Landsteiner. Later, studies showed that blood group was a risk factor for some diseases, such as peptic ulcer and diabetes [20]. Many studies have been performed on the blood group as a risk factor of cardiovascular diseases, and some of these studies have controversial results.

\section{Objectives}

There are a lot of contradictions on the effect of mycoplasma pneumonia, Helicobacter pylori, and blood group on the incidence of myocardial infarction in many studies, which can be attributed to ethnical and racial issues. Therefore, this study was performed to determine the correlation of AMI with mycoplasma pneumonia (through specifying the level of IgG), Helicobacter pylori (through specifying the level of IgA and IgG), and blood groups (through back-type method) in Qazvin. If there is a strong correlation found between AMI and Helicobacter pylori, mycoplasma pneumonia and blood groups, these infections will be treated considering that they are risk factors for AMI, high risk blood groups will be identified, and infections will be treated timely in order to reduce the incidence of AMI.

\section{Materials and Methods}

This case-control study was performed in teaching hospitals in Qazvin in 2013. Firstly, the blood sera of patients with infarction (based on the inclusion criteria of the study, the AMI was diagnosed if there were at least two of the following conditions: 1) a significant increase in cardiac enzymes, 2) clinical symptoms, such as chest pain and perspiration, and 3) changes in electrocardiogram; people with a history of using antibiotics were excluded) were collected and frozen as the samples of the case group. The blood sera of some other patients in other wards of the hospital with the same age and sex as the first group and without a history of AMI were collected as the samples of the control group.( from ethical point of view we only used diagnostic patient samples sent for other purposes.

Upon completion of the sample size of both groups, Abcam's anti-Mycoplasma pneumonia IgG and $\mathrm{H}$. pylori IgG and IgA Human in vitro ELISA (Enzyme-Linked Immunosorbent Assay) kits were designed for the accurate qualitative measurement of antibodies against Mycoplasma pneumonia and H. pylori. A 96-well plate has been precoated with Mycoplasma pneumonia and $H$. pylori antigens to bind cognate antibodies. Controls or test samples were added to the wells and incubated. Following washing, a horseradish peroxidase (HRP) labelled anti-Human IgG or IgA conjugates were added to the wells, which binds to the immobilized specific antibodies. TMB was then catalyzed by the HRP to produce a blue color product that changes to yellow after adding an acidic stop solution. The density of yellow coloration is directly proportional to the amount of IgA and IgG of samples captured in plate.

Blood groups were determined through back-type method. In this method the liquid part of blood without cells (serum) is mixed with blood cells that is known to be type A and type B. Persons with type A blood have anti-B antibodies, and those with type B blood have anti-A antibodies. Type O blood contains both types of antibodies. These two steps can accurately determine blood type.

The results of each patient's blood group; the level of specific antibodies; and demographic and clinical information including the age, sex, and level of CPK and CPK-MB enzymes were written in their questionnaires (presented at the end of manuscript), and analyzed using SPSS software.

\section{Results}

The results showed that men and women of the case group comprised $63.3 \%$ and $36.7 \%$, respectively; and men 
and women of the control group comprised $67.8 \%$ and $32.2 \%$, respectively. Based on Chi-square test, there was no significant difference between the case and control group $(\mathrm{P}>0.05)$ (Table 1). Mean age of the patients in the case and control group was 58.6 years and 58 years, respectively, and the Chi-square test did not show a significant difference in this regard $(\mathrm{P}>0.05)$. The significant increase in cardiac enzymes, which was one of diagnostic parameters for AMI in patients (including CPK and CPK-MB), was examined in the case and control groups; mean level of CPK in the case and control group was 1368 and 80, respectively, and mean level of CPK-MB in the case and control group was 132 and 5, respectively. The difference between the two groups was quite significantin terms of both enzymes $(\mathrm{P}<0.05)$ (Table 1$)$.

Helicobacter pylori infection, as determined by the level of IgG, was negative in $1.1 \%$, borderline in $5.6 \%$, and positive in $93.3 \%$ in the case group and negative in $5.6 \%$, borderline in $10 \%$, and positive in $84.4 \%$ in the control group. According to the Chi-square test, the difference between the two groups was significant $(\mathrm{P}<0.05)$ (Table 2 and Figure 1).

The results showed that the level of Helicobacter pylori IgA was negative in $20 \%$, borderline in $26.7 \%$, and positive in $53.3 \%$ in the case group and negative in $12.2 \%$, borderline in $20 \%$, and positive in $67.8 \%$ in the control group. Based on the Chi-square test, the difference between the two groups in this regard was not significant $(\mathrm{P}>0.05)$ (Table 2 and Figure 2).

Table 1. Age distribution in the case and control group.

\begin{tabular}{cccc}
\hline Group & Number & Mean & Standard deviation \\
Case & 90 & 58.57 & 15.779 \\
Control & 90 & 57.98 & 14.973 \\
Total & 180 & 58.12 & 15.344 \\
\hline
\end{tabular}

Table 2. Overall results.

\begin{tabular}{|c|c|c|c|c|c|c|}
\hline \multicolumn{7}{|c|}{ Group } \\
\hline & \multicolumn{2}{|c|}{ Case } & \multicolumn{2}{|c|}{ Control } & \multicolumn{2}{|c|}{ Total } \\
\hline & Number & Percentage & Number & Percentage & Number & Percentage \\
\hline Men & 57 & 63.3 & 61 & 67.8 & 118 & 65.6 \\
\hline Women & 33 & 36.7 & 29 & 32.2 & 62 & 34.4 \\
\hline Negative IgG.HP & 1 & 1.1 & 5 & 5.6 & 6 & 3.3 \\
\hline Borderline IgG.HP & 5 & 5.6 & 9 & 10 & 14 & 7.8 \\
\hline Positive IgG.HP & 84 & 93.3 & 76 & 84.4 & 160 & 88.9 \\
\hline Negative IgA.HP & 18 & 20 & 11 & 12.2 & 29 & 16.1 \\
\hline Borderline IgA.HP & 24 & 26.7 & 18 & 20 & 42 & 23.3 \\
\hline Positive IgA.HP & 48 & 53.3 & 61 & 67.8 & 109 & 60.6 \\
\hline Negative IgG.MP & 16 & 17.8 & 25 & 27.8 & 41 & 22.8 \\
\hline Borderline IgG.MP & 5 & 5.6 & 2 & 2.2 & 7 & 3.9 \\
\hline Positive IgG.MP & 69 & 76.7 & 63 & 70 & 132 & 73.3 \\
\hline O blood group & 27 & 30.7 & 21 & 23.3 & 48 & 27 \\
\hline AB blood group & 12 & 13.6 & 19 & 21.1 & 31 & 17.4 \\
\hline A blood group & 30 & 34.1 & 25 & 27.8 & 55 & 30.9 \\
\hline B blood group & 19 & 21.6 & 25 & 27.8 & 44 & 24.7 \\
\hline
\end{tabular}




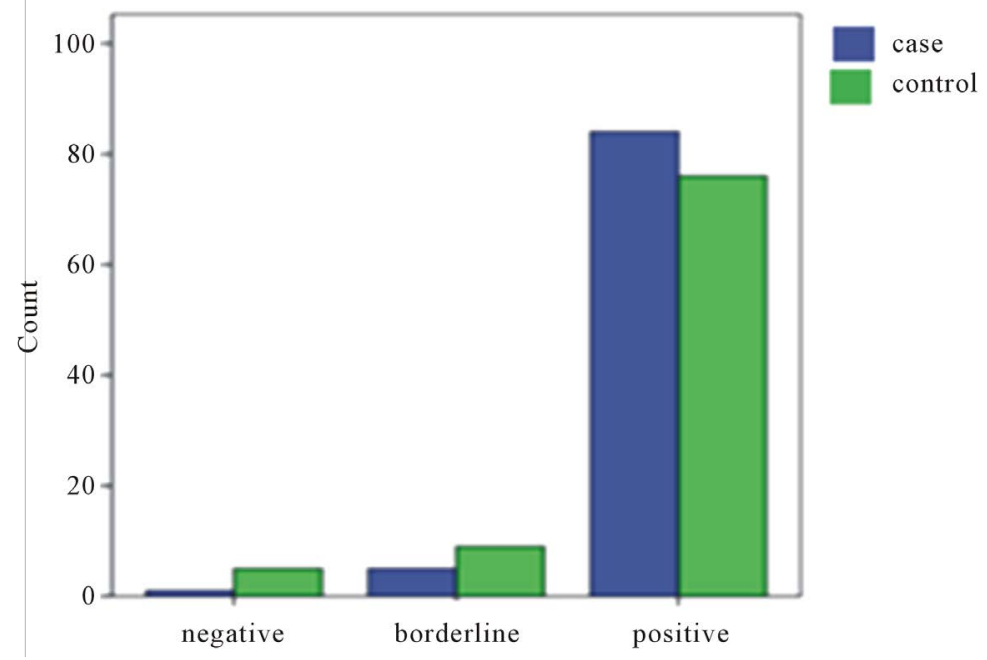

Figure 1. Comparison of the case and control groups in terms of the level of IgG.HP.

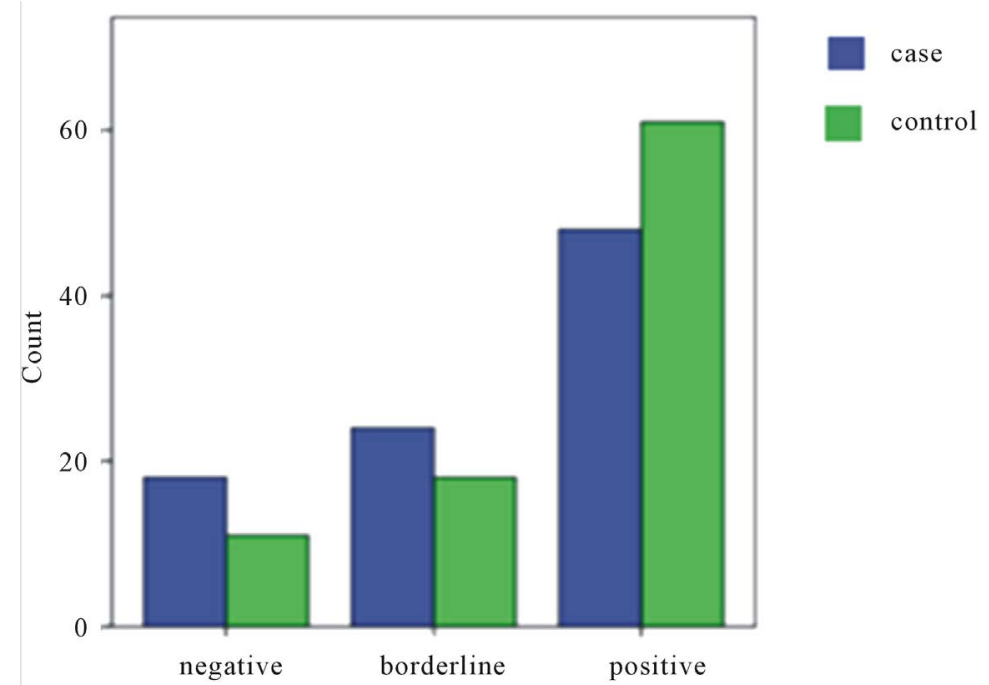

Figure 2. Comparison of the case and control groups in terms of the level of IgA.HP.

The level of mycoplasma pneumonia IgG, which showed the infection in patients, was negative in $17.8 \%$, borderline in $5.6 \%$, and positive in $76.7 \%$ in the case group and negative in $27.8 \%$, borderline in $2.2 \%$, and positive in $70 \%$ in the control group. Based on the Chi-square test, there was no significant difference between the two groups in this regard $(\mathrm{P}>0.05)$ (Table 2 and Figure 3).

The results on testing the ABO blood groups showed that $23.3 \%, 21.1 \%, 27.8 \%$, and $27.8 \%$ of the patients with $\mathrm{AMI}$ in the case group had the blood group $\mathrm{O}, \mathrm{AB}, \mathrm{A}$, and $\mathrm{B}$, respectively, and $30.7 \%, 13.6 \%, 34.1 \%$, and $21.6 \%$ of the people in the control group had the blood group $\mathrm{O}, \mathrm{AB}, \mathrm{A}$, and $\mathrm{B}$, respectively. So the analysis of results did not show a significant difference between case and control group in terms of ABO blood groups ( $\mathrm{P}>$ 0.05) (Table 2 and Figure 4).

\section{Discussion}

This study examined the correlation of AMI with Helicobacter pylori and mycoplasma pneumonia and blood group. Using the case-control method, a number of patients with a history of AMI and a number of patients without a history of AMI were respectively selected as the case and control group. The case-control method was 


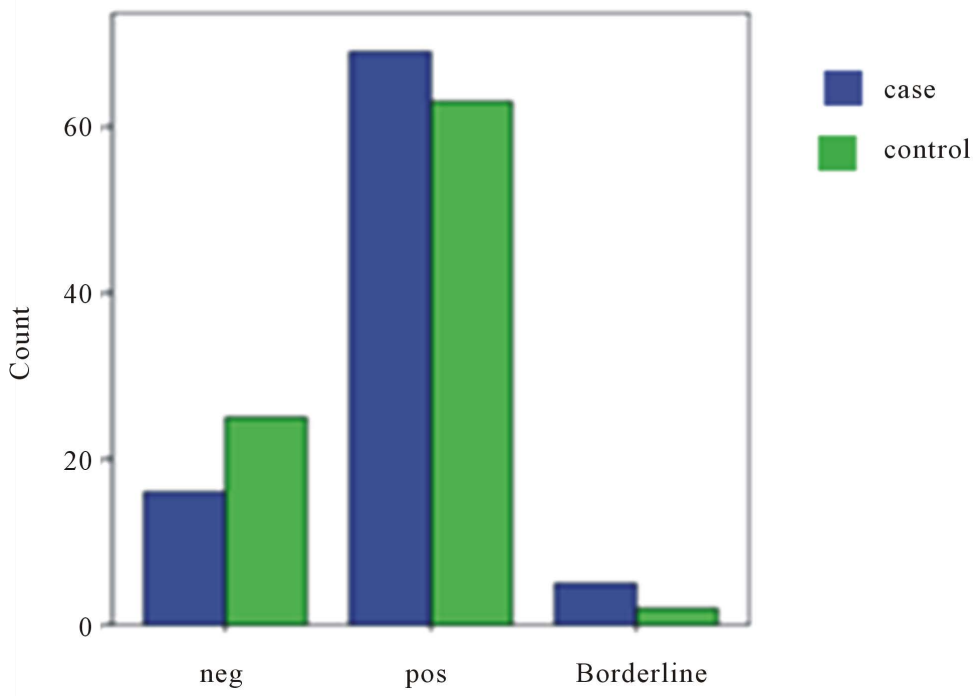

Figure 3. Comparison of the case and control groups in terms of the level of IgG.MP (mycoplasmapneumonia).

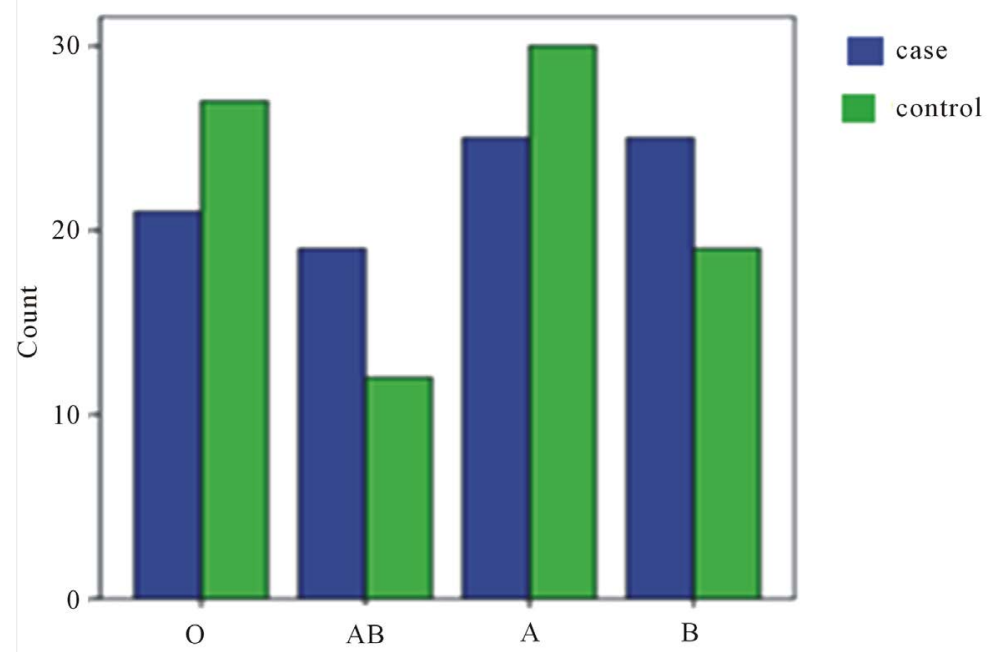

Figure 4. Comparison of the case and control groups in terms of the blood group.

used in order to express the variation in independent variables and find the risk factor of the disease.

Some of the methods that determine infection with Helicobacter pylori directly or non-serologically include biopsy, culture, PCR for Helicobacter pylori, one-minute urease test of the biopsy sample, and urease breath test, which are followed by technical, administrative, and financial problems for a case-control study.

Sayah et al.'s study was the most recent case-control study performed in Qazvin on 80 patients going to Qazvin's Bu Ali Hospital using the urease breath test. Results of current study showed the probable effect of Helicobacter pylori on the course of atherosclerosis and introduced the Helicobacter pylori as a transmittable risk factor for the coronary heart disease [21].

A part of the present study examined the serological reaction of body against the infectious agent, particularly the two classes A and G Helicobacter pylori antibodies separately and in combination.

However, despite the importance of the serological diagnosis of infectious agents, the body immune response against the agent might affect the serological diagnosis and consequently the specificity of the test. This might be the main reason for the differences and contradictions in studies [22]-[24].

Results of the present study showed a significant difference between the case and control group in terms of 
the level of Helicobacter pylori IgG. The result conformed to that of some studies [5] [25]-[30] and disagreed with some other studies [24] [31] [32]. It seems that these studies differ from one another in terms of the sample size and also the sampling method for the case and control group.

Present study did not show a significant difference between the case and control group in terms of the level of Helicobacter pylori IgA (P > 0.05). A few studies have focused on IgA [31] [32]. In this respect, it seems that although a moderate correlation can be assumed between Helicobacter pylori in terms of IgG seropositivity and incidence of MI, the correlation is not definite, and such a correlation should be proved through broader clinical trials and using more definitive parameters.

In another part of the present study, serological reactions were used to examine infection with mycoplasma pneumonia considering that this bacterium could increase the antibody in patients' serum, and acute attacks caused by coronary artery atherosclerosis often occurred after middle age, and there was a high risk for infecting with mycoplasma pneumonia in these ages. Moreover, it seems that the measurement of the IgG antibodies specific to mycoplasma pneumonia provides useful information about any previous infections with this microorganism, as many studies only measured the above antibody [10] [16]. However, some other studies have also determined the level of other antibodies, such as IgA and IgM [33].

The analysis of the difference between the infection with mycoplasma pneumonia and incidence of AMI showed no significant difference between the case and control group in terms of the level of IgG antibody ( $\mathrm{P}>$ 0.05). In this regard, $76.7 \%$ of the case group and $70 \%$ of the control group were positive for IgG, and there was no difference between the case and control group in terms of the mean level of the antibody. Ponka et al.'s study also did not show any significant correlation between the case and control group in terms of IgG antibody titer [10].

Chlamydia pneumoniae and mycoplasma pneumonia are bacterial agents, and several studies have been conducted on their role as predisposing factors of atherosclerosis and MI [9] [10] [15]-[17] [34]. Interestingly, infection with the two agents concurrently seems to have a stronger impact than infection with one of these agents; however, the present study did not examine the effect of infection with chlamydia pneumonia. Some studies introduced the effect of mycoplasma and chlamydia as a risk factor [9] [15]-[17] and some studies did not show any significant correlation. In Poorahmad et al.'s study, chlamydia pneumonia increased the risk of AMI less than mycoplasma did $(\mathrm{OR}=2.3)$ [10] [34]-[36].

Hosseinian et al.'s study showed that failure to perform a standard immunofluorescence test and also the variability of cut-off values in taking the ELISA tests positive were problems that were considered as the causes of differences in interpretation of the results of serological tests in different studies [34]. Therefore, regarding the contradictions in determining the effect of the level of mycoplasma antibodies, it seems that the main role of these agents in incidence of cardiovascular involvements is determined through indicating the pathogen or genome of the disease at the site of involvement (atheromatous plaques), which is very difficult in practice.

The possession of a specific blood group has been introduced as one of the genetic factors involved in heart diseases, and many studies have been performed to examine the correlation of blood group with cardiovascular diseases [20] [37]-[46]. Some studies found a specific blood group as a risk factor for heart diseases [37]-[42]. However, some other studies did not find any significant correlation between blood group and heart diseases [20] [45] [46]. Results of the present study showed no significant correlation between ABO blood groups and AMI ( $P>0.05)$. The studies performed on the effect of blood group on the incidence of AMI found that blood groups $\mathrm{A}, \mathrm{B}$, and $\mathrm{AB}$ as the most involved blood groups in AMI [39] [42] [47]-[55]. The studies showed a correlation between the blood group and heart disease found different groups of blood as the risk factor; one reason might be the different distribution of blood groups in different parts of the world [55]-[58]. Some studies showed a correlation between blood group and thrombosis of the lower extremities [59]-[61]. An increase in factor VIII and von Willebrand factor and decrease in APTT have been observed in patients without the blood group O (with other ABO blood groups), which increased the risk of thrombosis [47] [59]-[65].

In studies performed by Allen et al. [50] Tarjan et al. [43] and Rosen berg et al. [52] and some other studies, blood group A increased the risk of heart diseases. Despite the lack of correlation between blood groups and AMI in the case and control group in the present study, the frequency of the blood group A in the case group was higher than other blood groups (34.1\%).

\section{Conclusion and Recommendation}

This study did not show any significant difference between the two groups in terms of the level of IgG except 
for the infection with Helicobacter pylori. However, more studies should be performed at local and national levels in order to find the role of risk factors of AMI in each region.

\section{Acknowledgements}

The authors hereby appreciate all the personnel of the laboratories in Bu Ali, Velayat and Razi Hospitals and Mrs. Razieh Ashuri.

\section{References}

[1] Miles, W.M., Williams, F.C. and Zipes, D.P. (2001) Cardiovascular Disease Andereoli TE Essentials of Medicine.

[2] Pilotto, A., Rumor, F. and Franceschi, M. (1999) Lack of Association between Helicobacter pylori Infection and Extracardiac Atherosclerosis in Dyspepetic Elderly Subjects. Ageing, 28, 367-371.

[3] Pasceri, V., Cammarota, G., Patti, G., et al. (1998) Association of Virulent Helicobacter pylori Strains with Ischemic Heart Disease. Circulation, 97, 1675-1679. http://dx.doi.org/10.1161/01.CIR.97.17.1675

[4] Laurial, A., Bloigu, A. and Nayha, S. (1999) Association of Helicobacter pylori Infection with Elevated Serum Lipids. Atherosclerosis, 142, 207-210. http://dx.doi.org/10.1016/S0021-9150(98)00194-4

[5] Pellicano, R., Mazzarello, M.G. and Morelloni, S. (1999) Acute Myocardial Infarction and Helicobacter pylori Seropositivity. International Journal of Clinical \& Laboratory Research, 97, 1675-1679.

[6] Pieniazek, P., Karczewska, E. and Duda, A. (1999) Association of Helicobacter pylori Infection with Coronary Heart Disease. Journal of Physiology and Pharmacology, 50, 743-751.

[7] Rathbone, B., Martin, D. and Stephens, J. (1996) Helicobacter pylori Seropositivity in Subjects with Acute Myocardial Infarction. Heart, 76, 308-311. http://dx.doi.org/10.1136/hrt.76.4.308

[8] Grabczewska, Z., Nartowicz, E., Kubica, J. and Rosc, D. (2006) Endothelial Function Parameters in Patients with Unstable Angina and Infection with Helicobacter pylori and Chlamydia. European Journal of Internal Medicine, 17, 339-342. http://dx.doi.org/10.1016/j.ejim.2006.02.005

[9] Momiyama, Y., Ohmori, R., Tanigvchi, H., Nakamura, H. and Ohsuzu, F. (2005) Association of Mycoplasma Pneumonia Infections with Coronary Artery Disease and Its Interaction with Chlamydial Infection. Atherosclerosis, 180, 209-210.

[10] Ponka, A., Jalanko, H., Ponka, T. and Stenvik, M. (1981) Association of Mycoplasma Pneumonia Infections with Coronary Artery Disease and Its Interaction with Chlamydial Infection. Annals of Clinical Research, 13, 429-432.

[11] Maresh, H., Klimek, I. and Quineiliani, R. (1977) Myocardial Dysfunction and Hemolytic Anemia in a Patient with Mycoplasma pneumoniae Infection. Chest, 71, 410-413. http://dx.doi.org/10.1378/chest.71.3.410

[12] Mackay, A., Watt, J. and Jones, G. (1975) Myocarditis Associated with Mycoplasma pneumoniae Infection. Practioner, 390-392.

[13] Ponka, A. (1979) Carditis Associated with Mycoplasma pneumoniae Infection. Acta Medica Scandinavica, 206, 77-86. http://dx.doi.org/10.1111/j.0954-6820.1979.tb13473.x

[14] Paz, A. and Potasman, I. (2002) Mycoplasma-Associated Carditis. Cardiology, 97, 83-88. http://dx.doi.org/10.1159/000057677

[15] Ramires, J.A. and Higuchi, M.L. (2002) Mycoplasma pneumoniae and Chlamydia pneumoniae Are Associated to Inflammation and Rupture of the Atherosclerotic Coronary Plaques. Revista Espanola de Cardiologia, 55, S2-S9.

[16] Higuchi, M.L., Sambiase, N. and Palomino, S. (2000) Detection of Mycoplasma pneumoniae and Chlamydia pneumoniae in Rupeured Atherosclerotic Plaques. Brazilian Journal of Medical and Biological Research, 33, 1023-1026. http://dx.doi.org/10.1590/S0100-879X2000000900005

[17] Higuchi, M.L., Reis, M.M. and Sambiase, N.V. (2003) Coinfection with Mycoplasma pneumoniae and Chlamydia pneumoniae in Ruptured Plaques Associated with Acute Myocardial Infarction. Arquivos Brasileiros de Cardiologia, 81, 12-22. http://dx.doi.org/10.1590/S0066-782X2003000900001

[18] Bontti, P.O., Lerman, L.O. and lerman, A. (2003) Endothelial Dysfunction a Marker of Atherosclerotic Risk. Arteriosclerosis, Thrombosis, and Vascular Biology, 23, 168-175. http://dx.doi.org/10.1161/01.ATV.0000051384.43104.FC

[19] Higuchi, M.L. and Ramires, J.A. (2002) Infectious Agents in Coronary Atheromas: A Possible Role in the Pathogenesis of Plaque Rupture and Acute Myocardial Infarction. Revista do Instituto de Medicina Tropical de São Paulo, 44, 217-224. http://dx.doi.org/10.1590/S0036-46652002000400007

[20] Lutfullah, Akhtar, B., Quraishi, N.U.S., Hanif, A., Khan, B.Z. and Bukhshi, I.M. (2010) Association of ABO Blood Groups and Major Ischemic Heart Disease Risk Factors. Ann Anes, 16, 189-193. 
[21] Sayyah, S., Akbarian, M., Abdollah-Salimi, S., Tavakoli, M. and Pahlevan, A.A. (2012) AA Coexistence of Gastric Helicobacter pylori Infection and Coronary Artery Diseases in Qazvin (Iran). JQUMS, 16, 36-43.

[22] Nakić, D., Vcev, A., Jović, A., Patrk, J., Zekanović, D., Klarin, I., et al. (2011) Helicobacter pylori Infection and Acute Myocardial Infarction. Collegium Antropologicum, 35, 781-785.

[23] Danesh, J., Wong, Y. and Ward, M. (1999) Chronic Infection with Helicobacter pylori, Chlamydia pneumoniae or Cytomegalovirus: Population Based Study of Coronary Heart Disease. Heart, 81, 245-247. http://dx.doi.org/10.1136/hrt.81.3.245

[24] Bahar, M.A., Faghihi Kashani, A. and Haghighat, P. (2004) Association between Helicobacter pylori Infection and Coronary Heart Disease. Journal of Iran University of Medical Sciences, 39, 22-13.

[25] Zhu, J., Quyyumi, A.A., Muhlestein, J.B., Nieto, F.J., Horne, B.D., Zalles-Ganley, A., Anderson, J.L. and Epstein, S.E. (2002) Lack of Association of Helicobacter pylori Infection with Coronary Artery Disease and Frequency of Acute Myocardial Infarction or Death. The American Journal of Cardiology, 89, 155-158. http://dx.doi.org/10.1016/S0002-9149(01)02192-0

[26] Mandell, M.A., Goggin, P.M. and Molineaux, N. (1994) Relation of Helicobacter pylori Infection and Coronary Heart Disease. Heart, 71, 437-439. http://dx.doi.org/10.1136/hrt.71.5.437

[27] Raygan, F., Khorasanifar, H., Momen Heravi, M., Arj, A. and Akbari, H. (2009) The Association between Acute Myocardial Infarction and Anti Helicobacter pylori Antibody. Zahedan Journal of Research in Medical Sciences, 11.

[28] Rahnema, B., Zadegan, N. and Fatahi, E. (2001) Survey on the Association of Seropositivity of H. pylori IgG with Acute Myocardial Infarction. Journal of Kerman University of Medical Sciences, 8, 66-73.

[29] Rahimi, B., Daneshpajouh, M. and Ahsani, S. (2001) Cardiovascular Disease and Chlamydia, Helicobacter pylori and Cytomegalovirus Infection. Pejouhandeh Quarterly Research Journal, 24, 331-334.

[30] Azarkar, Z., Jafarnejad, M. and Sharifzadeh, G. (2011) The Relationship between Helicobacter pylori Infection and Myocardial Infarction. Caspian Journal of Internal Medicine, 2, 222-225.

[31] Hara, K., Morita, Y., Kamihata, H., Iwasaka, T. and Takahashi, H. (2001) Evidence for Infection with Helicobacter pylori in Patients with Acute Myocardial Infarction. Clinica Chimica Acta, 313, 87-94. http://dx.doi.org/10.1016/s0009-8981(01)00654-4

[32] Bazzazi, H., Ghaemi, E. and Ramazani, M. (2010) The Seroepidemiology of the Chronic Infections in Patients with Myocardial Infarction in North of Iran. Journal of Research in Medical Sciences, 15, 116-119.

[33] Basinkevich, A.B., Shakhnovich, R.M., Martynova, V.R., Kolkova, N.I., Rakovskaia, I.V. and Karazhas, N.V. (2003) Role of Chlamydia, Mycoplasma and Cytomegalovirus Infection in the Development of Coronary Artery Disease. Kardiologiia, 43, 4-9.

[34] Hosinian, A., Habib Zadeh, S., Sadeghieh Ahari, S. and Mokhtar Por, A. (2007) The Study of Previous Contact with Chlamydia pneumoniae in Patients with Myocardial Infarction. Ardabil University of Medical Sciences \& Health Services, 7, 35-40.

[35] Pourahmad, M. (2005) A Study on the Relationship between Acute Myocardial Infarction and Chlamydia pneumoniae. Scientific Medical Journal of Ahwaz University of Medical Sciences, 4, 147-151.

[36] Grau, A.J., Buggle, F., Heindl, S., Steichen-Wiehn, C., Banerjee, T., Maiwald, M., Rohlfs, M., Suhr, H., Fiehn, W., Becher, H. and Hacke, W. (1995) Recent Infection as a Risk Factor for Cerebrovascular Ischemia. Stroke, 26, 373-379. http://dx.doi.org/10.1161/01.STR.26.3.373

[37] Platt, D., Muhlberg, W., Kiehl, L. and Schmitt-Ruth, R. (1985) ABO Blood Group System, Age, Sex, Risk Factors and Cardiacinfarction. Archives of Gerontology and Geriatrics, 4, 241-249. http://dx.doi.org/10.1016/0167-4943(85)90006-8

[38] Stakishaitis, D.V., Ivashkiavichene, L.I., and Narvilene, A.M. (1991) Atherosclerosis of the Coronary Arteries and the Blood Group in the Population of Lithuania. Vrachebnoe Delo, 8, 55-57.

[39] Whincup, P.H., Cook, D.G., Phillips, A.N. and Shaper, A.G. (1990) ABO Blood Group and Ischemic Heart Disease in British Men. BMJ, 300, 1679-1682. http://dx.doi.org/10.1136/bmj.300.6741.1679

[40] Akhund, I.A., Alvi, I.A., Ansari, A.K., Mughal, M.A. and Akhund, A.A. (2001) A Study of Relationship of ABO Blood Groups with Myocardial Infarction and Angina Pectoris. Journal of Ayub Medical College, Abbottabad, 13, 25-26.

[41] Stakisaitis, D., Maksvytis, A., Benetis, R. and Viikmaa, M. (2002) Coronary Atherosclerosis and Blood Groups of ABO System in Women. Medicina, 38, 230-235.

[42] Tarjan, Z., Tonelli, M., Duba, J. and Zorandi, A. (1995) Correlation between ABO and Rh Blood Group: Serum Cholesterol and Ischemic Heart Disease in Patients Undergoin Coronarography. Orvosi Hetilap, 136, 767-769.

[43] Amirzadegan, A., Salarifar, M., Sadeghian, S., Davoodi, G., Darabian, C. and Goudarzynejad, H. (2006) Correlation 
between ABO Blood Group, Major Risk Factors and Coronary Artery Disease. International Journal of Cardiology, 110, 256-258. http://dx.doi.org/10.1016/j.ijcard.2005.06.058

[44] Kanbay, M., Yildirir, A., Ulus, T., Bilgi, M., Kucuk, A. and Muderrisoglu, H. (2006) Rhesus Positivity and Low High-Density Lipoprotein Cholesterol: A New Link? Asian Cardiovascular \& Thoracic Annals, 14, 119-121. http://dx.doi.org/10.1177/021849230601400208

[45] Biancari, F., Satta, J., Pokela, R. and Juvonen, T. (2003) ABO Blood Group Distribution and Severity of Coronary Artery Disease among Patients Undergoing Coronary Artery Bypass Surgery in Northern Finland. Thrombosis Research, 108, 195-196. http://dx.doi.org/10.1016/S0049-3848(03)00003-3

[46] Ibrahim, S., Orhan, O., Vedat, D., Eren, G.S. and Mehmet, M.A. (2008) ABO Blood Group Distribution and Major Cardiovascular Risk Factors in Patients with Acute Myocardial Infarction. Blood Coagulation \& Fibrinolysis, 19, 231 234. http://dx.doi.org/10.1097/MBC.0b013e3282f54522

[47] Meade, T.W., Cooper, J.A., Stirling, Y., Howarth, D.J., Ruddock, V. and Miller, G.J. (1994) Factor VIII, ABO Blood Group and the Incidence of Ischaemic Heart Disease. British Journal of Haematology, 88, 601-607. http://dx.doi.org/10.1111/j.1365-2141.1994.tb05079.x

[48] Von Beckerath, N., Koch, W., Wemer, M., Mehilli, J., Gorchakova, O., Braunschomig, A., et al. (2004) ABO Locus O1 Allele and Risk of Myocardial Infarction. Blood Coagulation and Fibrinolysis, 15, 61-67. http://dx.doi.org/10.1097/00001721-200401000-00010

[49] Bronte-Stewart, B., Botha, M.C. and Krut, L.H. (1962) ABO Blood Groups in Relation to Ischemic Heart Disease. BMJ, 16, 1646-1650. http://dx.doi.org/10.1136/bmj.1.5293.1646

[50] Allan, T.M. and Dawson, A.A. (1968) ABO Blood Groups and Ischaemic Heart Disease in Men. Heart, 30, $377-382$. http://dx.doi.org/10.1136/hrt.30.3.377

[51] Havlic, R.J., Feineib, M. and Garrison, R.J. (1969) Blood Groups and Coronary Heart Disease. Lancet, 294, $269-270$. http://dx.doi.org/10.1016/S0140-6736(69)90036-1

[52] Rosenberg, L., Miller, D.R., Kawfman, D.W., Helmrich, S.P., Van de Carr, S., Stolley, P.D. and Shapiro, S. (1983) Myocardial Infarction in Women under 50 Years of Age. JAMA, 250, 2801-2806. http://dx.doi.org/10.1001/jama.1983.03340200035025

[53] Imam, F., Bhatti, A. and Lutfullah (2000) Blood Group as a Minor Risk Factor of Ischaemic Heart Disease. Medical Forum, 2, 1-4.

[54] Khan, I.A., Farid, M. and Qureshi, S.M. (2005) Relationship of Blood Group Aye with Ischemic Heart Disease. Pakistan Journal of Medical Sciences, 44, 15-19.

[55] Wazirali, H., Ashfaque, R.A. and Herzig, J.W. (2005) Association of Blood Group A with Increased Risk of Coronary Heart Disease in the Pakistani Population. Pakistan Journal of Physiology, 1, 10-12.

[56] Abdollahi, A.A., Qorbani, M. and Salehi, A. (2009) ABO Blood Groups Distribution and Cardiovascular Major Risk Factors in Healthy Population. Iranian Journal of Public Health, 38, 123-126.

[57] Shah, S.A.R. (1990) Frequency of Kell and ABO Blood Groups in a Section of Lahore Population. Pakistan Journal of Medical Research, 29, 134-137.

[58] Khattak, I.D., Khan, T.M. and Khan, P. (2008) Frequency of ABO and Rhesus Blood Groups in District Sawat, Pakistan. Journal of Ayub Medical College Abbottabad, 20, 127-129.

[59] Allan, T.M. (1976) ABO Blood Groups and Age Groups in Surgical Venous Thromboembolism. Atherosclerosis, 23, 141-142. http://dx.doi.org/10.1016/0021-9150(76)90124-6

[60] Jick, H. and Porter, J. (1978) Thrombophlebitis of the Lower Extremities and ABO Blood Type. Archives of Internal Medicine, 138, 1566-1567. http://dx.doi.org/10.1001/archinte.1978.03630350088024

[61] Gonzalez Ordonez, A.J., Medina Rodriguez, J.M., Martin, L., Alvarez, V. and Coto, E. (1999) The O Blood Group Protects against Venous Thromboembolismin Individuals with the Factor V Leiden but Not the Prothrombin (Factor II G20210A) Mutation. Blood Coagulation \& Fibrinolysis, 10, 303-307. http://dx.doi.org/10.1097/00001721-199907000-00013

[62] Thompson, S.G., Kienast, J., Pyke, S.D.M., Haverkate, F. and van de Loo, J.C.W. (1995) Hemostatic Factors and the Risk of Myocardial Infarction or Sudden Death in Patients with Angina Pectoris. European Concerted Action on Thrombosis and Disabilities Angina Pectoris Study Group. New England Journal of Medicine, 332, 635-641. http://dx.doi.org/10.1056/NEJM199503093321003

[63] Green, D., Jarrett, O., Ruth, K.J., Folsom, A.R. and Liu, K. (1995) Relationship among Lewis Phenotype, Clotting Factors, and Other Cardiovascular Risk Factors in Young Adults. Journal of Laboratory and Clinical Medicine, 125, 334-339.

[64] O’Donnell, J. and Laffan, M.A. (2001) The Relationship between ABO Histo-Blood Group, Factor VIII and von Wil- 
lebrand Factor. Transfusion Medicine, 11, 343-351. http://dx.doi.org/10.1046/j.1365-3148.2001.00315.x

[65] Souto, J.C., Almasy, L., Muniz-Diaz, E., Soria, J.M., Borrell, M., Bayen, L., et al. (2000) Functional Effects of the ABO Locus Polymorphism on Plasma Levels of von Willebrand Factor, Factor VIII, and Activated Partial Thromboplastin Time. Arteriosclerosis, Thrombosis, and Vascular Biology, 20, 2024-2028.

http://dx.doi.org/10.1161/01.ATV.20.8.2024 